\title{
Evolutionary Game Analysis of BIM Adoption among Stakeholders in PPP Projects
}

\author{
Chong Jia $\mathbb{D}^{D}$, Ruixue Zhang $\mathbb{D}$, and Dan Wang $\mathbb{C}$ \\ School of Business Administration, Liaoning Technical University, Huludao 125105, China \\ Correspondence should be addressed to Chong Jia; 826108193@qq.com
}

Received 18 March 2021; Revised 24 July 2021; Accepted 7 August 2021; Published 18 August 2021

Academic Editor: Daniele Salvati

Copyright ( 92021 Chong Jia et al. This is an open access article distributed under the Creative Commons Attribution License, which permits unrestricted use, distribution, and reproduction in any medium, provided the original work is properly cited.

\begin{abstract}
With the development of building information technology, Building Information Modeling (BIM) has become an important way to effectively solve the cross-organization information collaboration of Public-Private Partnership (PPP) projects, and how to promote the adoption of BIM in PPP projects has become a realistic problem to be solved urgently. This study discusses the adoption of BIM among stakeholders in PPP projects based on prospect theory and evolutionary game theory. A tripartite evolutionary game model including governments, social capitals, and contractors is established. The behavioral evolution mechanism of each stakeholder on BIM adoption is explored by analyzing the evolutionary equilibrium, and the key influencing factors of equilibrium strategy are analyzed by using numerical simulation. The results demonstrate that first, the degree of the cost to all stakeholders involved in the adoption of BIM, as well as the punishment for governments' passive promotion of BIM, the punishment for social capitals' passive adoption of BIM and the reward for contractors' active application of BIM are the key factors affecting evolutionary stability. Second, according to prospect theory, the main stakeholders usually make decisions through subjective judgment and perceived value which ultimately lead to deviation in their behaviors. The deviations will hinder the establishment of ESS point $(1,1,1)$ and make the system difficult to converge to the optimal state. Finally, from the perspective of governments, social capitals, and contractors, countermeasures and management implications are put forward to effectively promote the adoption of BIM in PPP projects.
\end{abstract}

\section{Introduction}

Public-Private Partnership (PPP) can not only save the costs for the government but also inject the private sector efficiency in the government sector domain [1]. It has been an important way to reshape the infrastructure construction industry in China [2,3]. Different from general construction projects, PPP projects always involve a complex network of public and private partners (designers, contractors, and operators) beginning in the planning stage of the projects $[4,5]$, with each of these partners having different priorities and leading to conflicting objectives [6]. During the long contract period, problems such as information asymmetry and poor communication often occur [7-10]. How to realize the effective cross-organizational collaboration between stakeholders of PPP projects has become one of the important factors affecting the performance and even the success or failure of PPP projects [11].
With the development of informatization in construction industry, Building Information Modeling (BIM) has been widely used in the whole process of construction projects and reshaping the production mode of the construction industry [12]. BIM is not a simple 3D modeling program. Its biggest feature is that it can carry a large amount of information of architectural models and can be applied in multiple fields. The advantages of BIM which considered to be the best way to solve the problem of cross-organizational collaboration in construction projects coincide well with the needs of PPP project life cycle management [13]. The key issue to promote the adoption of BIM in PPP projects is the behavior evolutionary among the major stakeholders such as government, social capital, and contractor. It can be seen that they usually have the common vision to achieve the project objectives but not the same in the collaborative adoption of BIM [14]. Some scholars have researched the adoption of BIM in construction industry 
based on evolutionary game theory. They mainly build the evolutionary game model of BIM adoption between two or three main stakeholders and analyzed the evolutionary mechanism or influencing factors [15-18]. But in existing literature, there is little research on BIM adoption in PPP projects. Chong Jia et al. build an evolutionary game model of BIM adoption between government and social capital in PPP projects and analyzed the stable equilibrium strategies and implementation conditions of both parties [19]. Then, the authors find that the existing research on behavior evolutionary of BIM adoption is all based on the expected utility theory. Prospect theory put forward by Daniel-Kahneman and Amos.Tversky pointed out that the behavior characteristics of the individual under the risk conditions are not consistent with the basic principle of the expected utility theory [20]. Individual behavior is not only completely following the utility maximization but also will be affected by a variety of psychological factors. In PPP projects, governments, social capitals, and contractors show the characteristics of bounded rationality under the influenced and interfered by uncertain factors such as environment, policy, and information [21]. The decision-making of them is on the basis of their own perceived profit and loss, so the expected utility theory which has been widely accepted for a long time is not suitable for the situation when people's psychological perception is uncertain [22]. The application of prospect theory can effectively solve the above problems, the evolutionary game model among stakeholders of PPP projects for the adoption of BIM can be build based on bounded rationality and psychological perception value, and the influence of individual psychological perception can be considered in the evolutionary game process. The following research questions will be answered in this study.

(i) What is the behavior evolution law of BIM adoption among stakeholders in PPP projects?

(ii) What are the influencing factors of behavior strategy selection for the adoption of BIM in PPP projects?

(iii) How to promote the adoption of BIM in PPP projects?

The research results will help to clarify the behavior evolution mechanism and the influencing factors of the evolutionary stabilization strategy (ESS) for adopting BIM among stakeholders in PPP projects, so as to improve the cross-organization information collaboration efficiency of PPP projects and promote the informatization of the construction industry. The application of prospect theory considering the psychological perception value will make evolutionary game more in line with reality. This study is structured as follows. First, we review the relevant literature and point out our research opportunities. Second, we build the tripartite evolutionary game model for adopting BIM and analyze the stability of stakeholders of PPP projects. Finally, we analyze the key influencing factors of behavior strategy by numerical simulation and put forward some management implications on the adoption of BIM in PPP projects.

\section{Related Literature}

2.1. Adoption of BIM in PPP Projects. Many scholars at home and abroad have studied the feasibility and applicability of BIM adoption in PPP projects. Porwal and Hewage proposed a new procurement framework for public facilities and services based on BIM and proved the feasibility of this method in public construction projects by example analysis [23]. Love et al. put forward that BIM can be used as a way to measure the life cycle performance of PPP projects and provide decision-makers with the key decision information across the whole life cycle [24]. Yin et al. proposed a set of VfM quantitative evaluation and financial affordability evaluation system based on BIM data, which effectively demonstrates the feasibility of PPP projects in different stages of the whole life cycle [25]. Wang et al. explored the application of BIM in the delicacy management of PPP projects and demonstrated its feasibility [26]. Chen and Chen analyzed the risk types of PPP projects' whole life cycle and constructed the risk management model of PPP projects based on BIM [27]. Jinhua Li and Zengzhao Zhang established the operation and supervision platform of PPP projects based on BIM and explored the application effect of BIM in the whole life cycle information management of PPP projects. Luo and Zhan [28] and Zhou and $\mathrm{Li}$ [29] discussed the specific application content of BIM in the whole process of project.

2.2. Evolutionary Game Theory. Evolutionary game theory is an application of the mathematical framework of game theory to the dynamics of animal conflicts [30,31]. Different from game theory, evolutionary game theory which is based on the assumption of bounded rationality not only considers the limited rationality of individuals but also dynamically adjusts their strategies through learning and imitation. It both well describes the dynamic evolutionary process among the core stakeholders and better explains the formation process of equilibrium [32,33]. The two most important concepts in evolutionary game theory are evolutional stability strategy (ESS) and replicator dynamics [34].

Evolutionary game theory provides a wide range of research tools; its application ranges from evolutionary biology extends to various fields such as natural science and social science and is especially widely used in economics. The research in this area applies evolutionary game theory in following main contexts: (1) the evolution of social customs, traditions, and norms. Peyton Young applied evolutionary game theory to analyze the relationship between the formation of social norms and social welfare [35]. Fudenberg and Harris applied evolutionary game theory to analyze the social learning process [36]. (2) The changes of the economic system and the evolution of market environment. Bester and Guth applied the evolutionary game theory to study the existence and evolutionary stability of human altruism in economic activities [37]. The evolution of market survival and market credit are both studied based on the theory $[38,39]$. (3) The research of enterprise organization, technology innovation, and strategy. Freidman and Fung applied evolutionary game to analyze the evolution of the 
organization mode of firms with and without trade based on American and Japanese firms [40]. Wang and Meng applied the evolutionary game theory to study the evolution of the cooperative competition mechanism of supply chain enterprises [41]. Following the development of the theory, it has been widely applied to a wider range of fields. For instance, Gao and Sheng analyzed evolutionary game theory in power market [42]. Yan Zhang and Mohsen Guizani described how to employ the theory in infrastructure-based wireless networks and multihop networks to reduce power consumption, while improving system capacity, decreasing packet loss, and enhancing network resilience [43]. Lu used the theory to analyze the strategy selection behavior among pollution-producing enterprises, environmental protection departments, and pollution-producing enterprises [44].

In construction industry, evolutionary game theory has been widely used to analyze the behavioral evolution mechanism of BIM adoption. For example, Qi Wang and Teng Wang constructed a tripartite evolutionary game model on BIM application among governments, enterprises, and consumers, which provided a reference for BIM application and promotion in Chinese construction industry [15]. Qiaoling Yin constructed evolutionary game models between government and enterprises as well as owner and contractors on BIM diffusion in prefabricated buildings, explored the key influencing factors, and put forward corresponding suggestions [16]. Tang et al. used evolutionary game theory to analyze behaviors evolution of BIM application in integrated facility management organization from six scenarios [17]. Jiaren Song used evolutionary game theory to build a dynamic model of the owner replication group and discussed the evolution strategy of incentives and developers for social stability, and finally put forward relevant suggestions to provide the beneficial reference for promoting BIM [18].

2.3. Prospect Theory. Prospect theory is the integration of psychological research into economic research and reveals the decision-making mechanism under uncertain conditions [45]. Different from expected utility theory, prospect theory finds through a series of experiments that people's decision choice depends on the gap between results and prospects, rather than the results themselves. When people make decisions, they have a preset reference point in mind, and then, they measure whether each outcome is above or below this reference point. For the return results above the reference point, people tend to show risk aversion and preference for certain small returns. For loss-type outcomes below the reference point, people show risk appetite again, hoping for good luck to avoid losses [46].

Initially, finance is the field of economics where prospect theory has been most actively applied [47]. The research in this area applies prospect theory in three main contexts: (1) the cross-section of average returns, where the goal is to understand why some financial assets have higher average returns than others. Benartzi and Thaler applied prospect theory to explain the famous equity premium puzzle: the fact that the average return of the US stock market has historically exceeded the average return of treasury bills by a much greater margin than predicted by traditional consumption-based models of asset prices [48]. (2) The aggregate stock markets. Barberis and Huang studied asset prices in a one-period economy populated by investors who derive prospect theory utility from the change in the value of their portfolios over the course of the period [49]. (3) The trading of financial assets over time. Frazzini found through the empirical that both individual investors and mutual fund managers have a greater propensity to sell stocks that have risen in value since purchase, rather than stocks that have fallen in value [50]. At present, the application of prospect theory has been quite extensive, including insurance, marketing, consumer behavior, and other aspects. For example, $\mathrm{Hu}$ and Scott argued that prospect theory offers a way of understanding why annuities are unpopular. In their framework, people think of an annuity as a risky gamble whose payoff, unknown at the moment of retirement, is the present value of the payouts to be received from the annuity before death, minus the amount initially paid for the annuity [51]. Köszegi and Rabin proposed a way of incorporating the ideas in prospect theory into a dynamic model of consumption choice. The model builds on the authors' earlier idea that expectations are an important reference point [52]. Vamvakas et al. proposed a novel dynamic spectrum management scheme for $5 \mathrm{G}$ nonorthogonal multiple access (NOMA) wireless networks based on prospect theory, where users are offered the option to transmit via licensed and unlicensed bands [53].

In construction industry, many scholars have introduced prospect theory into evolutionary games and used perceptual expectation function instead of the expected utility function, so as to better analyze behavior evolutionary problems. He et al. studied the economic interest game between the three stakeholders of government, social capital, and public in major engineering projects and analyzes its behavior. The three-way evolutionary game model based on prospect theory and the perceptual benefit matrix is constructed [22]. Zhou and Li established and analyzed the game revenue perception matrix which introduces the administrative supervision mechanism of higher-level government departments into PPP projects based on prospect theory and the assumption of bounded rationality, and the research considered that it is necessary to consider third parties from outside the regulatory structure to achieve effective regulation [54]. Zhang et al. constructed the expected utility model of PPP investors' investment decision based on prospect theory and considering the imperfect rational state of investors in the investment decision, and the research considered prospect theory is more suitable to study the decision behavior of PPP project investors compared with the traditional expected utility theory [55].

\section{Evolutionary Game Model Based on Prospect Theory}

Evolutionary game theory which has been widely used for behavioral strategy evolution mechanism analysis is applied to establish the behavioral evolutionary game model of BIM adoption. Based on the above background, evolutionary game based on expected utility does not consider the characteristics 
of psychological perception factors of PPP projects' stakeholders. Obviously, under the condition of bounded rationality, individual psychological perception often has a key influence on behavioral decision-making [46]. So, this study replaces the expected utility of the traditional evolutionary game with the value function $v\left(\Delta \omega_{i}\right)$ of prospect theory and replaces the actual probability with the weight function $\pi\left(p_{i}\right)$, so as to obtain the perceived value of the total expected utility of the strategy which can be expressed as

$$
V=\sum_{i} \pi\left(p_{i}\right) v\left(\Delta \omega_{i}\right)
$$

Therein, the value function $v\left(\Delta \omega_{i}\right)=$ $\left\{\begin{array}{ll}\left(\Delta \omega_{i}\right)^{\alpha} & \Delta \omega_{i} \geq 0 \\ -\lambda\left(-\Delta \omega_{i}\right)^{\beta} & \Delta \omega_{i}<0\end{array}\right.$, and the weight function $\pi\left(p_{i}\right)=P^{\gamma} /$ $\left[P^{\gamma}+(1-P)^{\gamma}\right]^{1 / \gamma}$. In the formula, $\Delta \omega_{i}$ is the difference between the actual income and the reference point when the behavior subject adopts strategy $i ; \alpha, \beta(0<\alpha<1,0<\beta<1)$ are the risk attitude coefficients which represent the degree of decline in the editor of the game subject's perceived value of profit and loss. The higher the value, the greater the degree of marginal decline. The loss avoidance coefficient is denoted by $\lambda(\lambda \geq 1)$, and the greater the value, the more sensitive the game subject to the loss. The actual occurrence probability of strategy $i$ is denoted by $p_{i}$, and the decision weight is denoted by $\pi\left(p_{i}\right)(\pi(0)=0, \pi(1)=1)$. When $p$ is very small, there will be $\pi\left(p_{i}\right)>p$, and when $p$ is very large, there will be $\pi\left(p_{i}\right)<p$. That is, low probability events are usually overestimated in prospect theory, while high probability events are usually underestimated. The construction of the multiagent evolutionary game model based on prospect theory can fully reflect the psychological perceived value of each stakeholder and is more conducive to clarifying the evolutionary game mechanism and influencing factors.

\subsection{Basic Assumptions and Evolutionary Game Strategies}

\subsubsection{Basic Assumptions}

Assumption 1. According to the above analysis, social capitals are the important subjects of BIM adoption in PPP projects, contractors are the implementation subject of the practical application of BIM, and governments are the driving subject of BIM adoption. Therefore, the behavior strategies of governments are set as \{positive promotion, passive promotion\}, the behavioral strategies of social capitals are set as \{positive adoption, passive adoption\}, and the behavioral strategies of contractors are set as \{positive application, passive application\}.

Assumption 2. The probability of "positive promotion" is set as $x(0 \leq x \leq 1)$, and the probability of "passive promotion" is equal to $1-x$. The probability of "positive adoption" is set as $y(0 \leq y \leq 1)$, and the probability of "passive adoption" is equal to $1-y$. The probability of "positive application" is set as $z(0 \leq z \leq 1)$ and the probability of "passive application" is equal to $1-z$.

Assumption 3. Governments, social capitals, and contractors will generate benefits and expenses when adopting different behavior strategies. The profit and loss indexes of each subject are given in Table 1 .

3.1.2. Game Strategies' Perceived Value of Profit and Loss. Based on the above assumptions, the profit and loss matrix of the perceived value among governments, social capitals, and contractors is constructed as given in Table 2 .

\subsection{Construction and Solution of the Evolutionary Game Model}

3.2.1. Replicator Dynamics Equation and Equilibrium Point Analysis of Governments. According to Table 2, we can get the perceived expected value $E_{g 1}$ of governments taking strategy of "positive promotion" and the perceived expected value $E_{g 2}$ of governments taking strategy of "passive promotion."

$$
\begin{aligned}
\mathrm{Eg} 1= & \mathrm{yz}(\operatorname{Rg} 1-\mathrm{Cg}-\mathrm{Sp})+y(1-z)(\operatorname{Rg} 1-\mathrm{Cg}-\mathrm{Sp}+\mathrm{Lc})+z(1-y)(\operatorname{Rg} 2-\mathrm{Cg}-\mathrm{Sp}+\mathrm{Lp}) \\
& +(1-y(1-z)(-\mathrm{Cg}+\mathrm{Lp}+\mathrm{Lc}-\mathrm{Sp})), \\
\mathrm{Eg} 2= & \mathrm{yz}(\operatorname{Rg} 1-\alpha \operatorname{Lg} 1)+y(1-z)(\operatorname{Rg} 2-\alpha \operatorname{Lg} 1)+z(1-y)(1-z)(-\operatorname{Lg}-\alpha \operatorname{Lg} 1) .
\end{aligned}
$$

Then, the average perceived expected value of governments is as follows:

$$
\overline{E_{g}}=x E_{g 1}+(1-x) E_{g 2} .
$$

Therefore, the replication dynamic equation of governments is as follows:

$$
\begin{aligned}
F(x) & =\frac{\mathrm{d} x}{\mathrm{~d} t}=x(\mathrm{Eg} 1-\overline{\mathrm{Eg}})=x(1-x)(\mathrm{Eg} 1-\mathrm{Eg} 2) \\
& =x(1-x)(-\mathrm{Cg}-\mathrm{Sp}+\mathrm{Lp}+\mathrm{Lc}+\mathrm{Lg}+\alpha \mathrm{Lg} 1-\mathrm{zLc}-\mathrm{yLp}-\mathrm{yLg})
\end{aligned}
$$


TABLE 1: The profit and loss indexes of stakeholders.

\begin{tabular}{|c|c|}
\hline Index & Explanation of index \\
\hline$R g 1$ & The benefit brought to governments when social capitals adopt BIM actively \\
\hline $\operatorname{Rg} 2$ & The benefit brought to governments when social capitals adopt BIM passively \\
\hline $\mathrm{Cg}$ & The cost of governments' promotion of BIM \\
\hline$S p$ & The subsidy provided by governments when social capitals adopt BIM actively \\
\hline$L p$ & The punishment imposed by governments when social capitals adopt BIM passively \\
\hline$L c$ & The punishment imposed by governments when contractors apply BIM passively \\
\hline $\operatorname{Lg}$ & $\begin{array}{c}\text { The adverse effects on the development of construction industry when governments promote BIM passively and social capitals } \\
\text { adopt BIM passively }\end{array}$ \\
\hline Lg1 & The punishment imposed by the superior supervision authority when governments promote BIM passively \\
\hline$\alpha$ & The probability of the superior supervision authority finding that governments promote BIM passively \\
\hline $\mathrm{Rp}$ & The benefit brought to social capitals when contractors applying BIM actively \\
\hline Cp1 & The cost of social capitals' positive adoption of BIM \\
\hline $\mathrm{Cp} 2$ & The cost of social capitals' passive adoption of BIM \\
\hline Lp1 & The adverse effects on social capitals when contractors apply BIM passively \\
\hline Sc & The reward provided by social capitals when contractors apply BIM actively \\
\hline Rc & The benefit obtained by contractors apply BIM actively \\
\hline $\mathrm{Cc}$ & The cost incurred by the contractors apply BIM actively \\
\hline Lc1 & $\begin{array}{l}\text { The compensation given by contractors undertaking passive application of BIM to social capitals undertaking positive adoption of } \\
\text { BIM when governments promote BIM actively }\end{array}$ \\
\hline Lc2 & $\begin{array}{l}\text { The compensation given by contractors undertaking passive application of BIM to social capitals undertaking positive adoption of } \\
\text { BIM when governments promote BIM passively }\end{array}$ \\
\hline
\end{tabular}

TABLE 2: The matrix of the perceived value of profit and loss among stakeholders.

\begin{tabular}{|c|c|c|c|c|c|}
\hline & & & & Govern & nts \\
\hline & Participants of th & rolutionary g & & $\begin{array}{l}\text { Positive promotion } \\
\qquad(x)\end{array}$ & $\begin{array}{l}\text { Passive promotion } \\
\qquad(1-x)\end{array}$ \\
\hline Social capitals & $\begin{array}{l}\text { Positive adoption } \\
\qquad(y)\end{array}$ & Contractors & $\begin{array}{l}\text { Positive application } \\
\qquad(z) \\
\text { Passive application } \\
\qquad(1-z) \\
\text { Positive application } \\
\qquad(z) \\
\text { Passive application } \\
\quad(1-z)\end{array}$ & $\begin{array}{c}\mathrm{Rg} 1-\mathrm{Cg}-\mathrm{Sp} \\
\mathrm{Rp}-\mathrm{Cp} 1-\mathrm{Sc}+\mathrm{Sp} \\
\mathrm{Rc}-\mathrm{Cc}+\mathrm{Sc} \\
\mathrm{Rg} 1-\mathrm{Cg}-\mathrm{Sp}+\mathrm{Lc} \\
\mathrm{Rp}-\mathrm{Cp} 1+\mathrm{Sp}+\mathrm{Lc} 1-\mathrm{Lp} 1 \\
-\mathrm{Lc}-\mathrm{Lc} 1 \\
\mathrm{Rg} 2-\mathrm{Cg}-\mathrm{Sp}+\mathrm{Lp} \\
\mathrm{Rp}-\mathrm{Cp} 2+\mathrm{Sp}-\mathrm{Lp}-\mathrm{Sc} \\
\mathrm{Rc}-\mathrm{Cc}+\mathrm{Sc} \\
-\mathrm{Cg}+\mathrm{Lp}+\mathrm{Lc}-\mathrm{Sp} \\
\mathrm{Rp}-\mathrm{Cp} 2+\mathrm{Sp}-\mathrm{Lp}-\mathrm{Lp} 1 \\
-\mathrm{Lc}\end{array}$ & $\begin{array}{c}\mathrm{Rg} 1-\alpha \mathrm{Lg} 1 \\
\mathrm{Rp}-\mathrm{Cp} 1-\mathrm{Sc} \\
\mathrm{Rc}-\mathrm{Cc}+\mathrm{Sc} \\
\mathrm{Rg} 1-\alpha \mathrm{Lg} 1 \\
\mathrm{Rp}-\mathrm{Cp} 1+\mathrm{Lc} 2-\mathrm{Lp} 1 \\
-\mathrm{Lc} 2 \\
\mathrm{Rg} 2-\mathrm{Lg}-\alpha \mathrm{Lg} 1 \\
\mathrm{Rp}-\mathrm{Cp} 2-\mathrm{Sc} \\
\mathrm{Rc}-\mathrm{Cc}+\mathrm{Sc} \\
-\mathrm{Lg}-\alpha \mathrm{Lg} 1 \\
\mathrm{Rp}-\mathrm{Cp} 2-\mathrm{Lp} 1 \\
0\end{array}$ \\
\hline
\end{tabular}

The first derivative of $x$ is equal to

$$
\begin{aligned}
\frac{d(F(x))}{\mathrm{d} x}= & (1-2 x)(-\mathrm{Cg}-\mathrm{Sp}+\mathrm{Lp}) \\
& +\mathrm{Lc}+\mathrm{Lg}+\alpha \operatorname{Lg} 1-\mathrm{zLc}-\mathrm{yL} \mathrm{p}-\mathrm{yLg})
\end{aligned}
$$

When $F(x)=0$ and $\mathrm{d}(F(x)) / \mathrm{d} x<0$, governments' strategy of "positive promotion" will be in a stable state.

Therefore, there will be $F(x) \equiv 0$ when $z=-\mathrm{Cg}-$ $y \mathrm{Sp}+\mathrm{Lp}+\mathrm{Lc}+\mathrm{Lg}-\mathrm{yLp}-\alpha \mathrm{Lg} 1 / \mathrm{Lc}$, and all the values of $x$ are in a stable state. When $z<-\mathrm{Cg}-\mathrm{ySp}+\mathrm{Lp}+$ $\mathrm{Lc}+\mathrm{Lg}-\mathrm{yLp}-\alpha \mathrm{Lg} 1 / \mathrm{Lc}$, there will be $d(F(x)) /\left.\mathrm{d} x\right|_{x=1}\langle 0$, and $x=1$ is the ESS of the system. When $z>-\mathrm{Cg}-\mathrm{ySp}+$ $\mathrm{Lp}+\mathrm{Lc}+\mathrm{Lg}-\mathrm{yLp}-\alpha \mathrm{Lg} 1 / \mathrm{Lc}$, there will be $d(F(x)) /$ $\left.\mathrm{d} x\right|_{x=0}<0$, and $x=0$ is the ESS of the system. The phase diagram of governments' behavioral strategy evolution is shown in Figure 1. The slant $z=-\mathrm{Cg}-\mathrm{ySp}+\mathrm{Lp}+\mathrm{Lc}+\mathrm{Lg}-$ $\mathrm{yLp}-\alpha \operatorname{Lg} 1 / \mathrm{Lc}$ divides the three-dimensional space $V=(x, y, z \mid, 0 \leq x \leq 1,0 \leq y \leq 1,0 \leq z \leq 1)$ into parts of $V 1$ and $V 2$. In part $V 1$, governments gradually evolved to $x=0$ and finally chose the strategy of "passive promotion." In part $V 2$, governments gradually evolved to $x=1$ and finally chose the strategy of "positive promotion."

\subsubsection{Replicator Dynamics Equation and Equilibrium Point} Analysis of Social Capitals. According to Table 2, we can get the perceived expected value $E_{p 1}$ of social capitals taking strategy of "positive adoption" and the perceived expected value $E_{p 2}$ of social capitals taking the strategy of "passive adoption." 


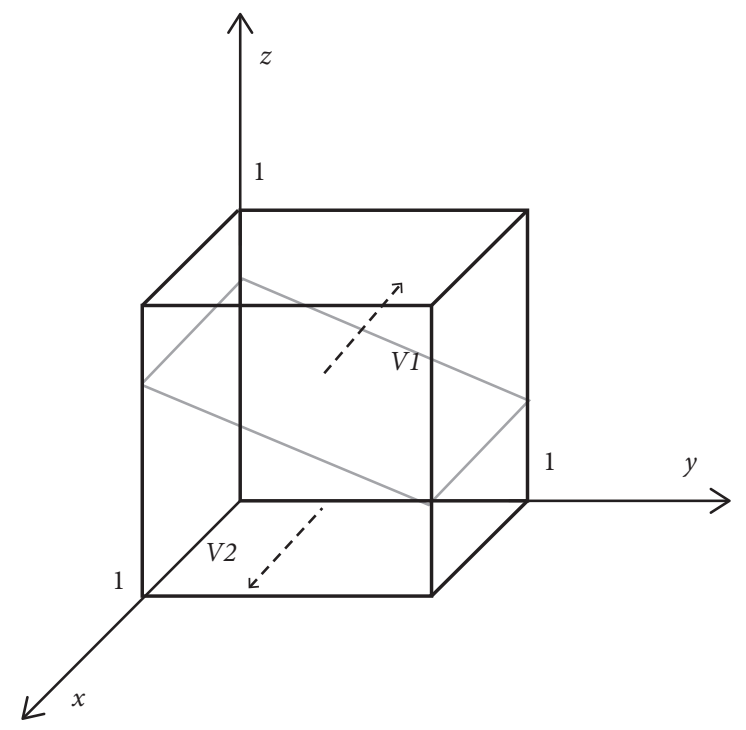

FIgURE 1: Phase diagram of governments' behavioral strategy evolution.

$$
\begin{aligned}
\mathrm{Ep} 1= & \mathrm{xz}(\mathrm{Rp}-\mathrm{Cp}-\mathrm{Sc}+\mathrm{Sp})+z(1-x)(\mathrm{Rp}-\mathrm{Cp} 1-\mathrm{Sc})+x(1-z)(\mathrm{Rp}-\mathrm{Cp} 1+\mathrm{Sp} \\
& +\mathrm{Lc} 1-\mathrm{Lp} 1)+(1-z)(1-x)(\mathrm{Rp} 1-\mathrm{Cp} 1+\mathrm{Lc} 2-\mathrm{Lp} 1) \\
\mathrm{Ep} 2= & \mathrm{xz}(\mathrm{Rp} 1-\mathrm{Cp} 2-\mathrm{Lp}-\mathrm{Sc}+\mathrm{Sp})+z(1-x)(\mathrm{Rp}-\mathrm{Cp} 2-\mathrm{Sc})+x(1-z) \\
& \cdot(\mathrm{Rp}-\mathrm{Cp} 2-\mathrm{Lp}+\mathrm{Sp}-\mathrm{Lp} 1)+(1-z)(1-x)(\mathrm{Rp}-\mathrm{Cp} 2-\mathrm{Lp}) .
\end{aligned}
$$

Then, the average perceived expected value of social capitals is as follows:

$$
\overline{E_{p}}=y E_{p 1}+(1-y) E_{p 2} .
$$

Therefore, the replication dynamic equation of social capitals is as follows:

$$
\begin{aligned}
F(y)= & \frac{\mathrm{d} y}{\mathrm{~d} t}=y(\mathrm{Ep} 1-\overline{\mathrm{Ep}})=y(1-y)(\mathrm{Ep} 1-\mathrm{Ep} 2) \\
= & y(1-y)(\mathrm{Cp} 2-\mathrm{Cp} 1+\mathrm{Lc} 2+x \mathrm{Lc} 1-x \mathrm{Lc} 2 \\
& -\mathrm{zLc} 2+\mathrm{xLp}-\mathrm{xzLc} 1+\mathrm{xzLc} 2) .
\end{aligned}
$$

The first derivative of $y$ is equal to

$$
\begin{aligned}
\frac{d(F(y))}{\mathrm{d} t}= & (1-2 y)(\mathrm{Cp} 2-\mathrm{Cp} 1+\mathrm{Lc} 2+\mathrm{xLc} 1-\mathrm{xLc} 2 \\
& -\mathrm{zLc} 2+\mathrm{xLp}-\mathrm{xzLc} 1+\mathrm{xzLc} 2) .
\end{aligned}
$$

When $F(y)=0$ and $d(F(y)) / \mathrm{d} y<0$, social capitals' strategy of "positive adoption" will be in a stable state. Therefore, there will be $F(y) \equiv 0$ when $z=\mathrm{Cp} 2-\mathrm{Cp} 1+\mathrm{Lc} 2$ $+x L c 1-x L c 2+x L p / L c 2+x L c 1-x L c 2$, and all the values of $y$ are in a stable state. When $z\langle\mathrm{Cp} 2-\mathrm{Cp} 1+\mathrm{Lc} 2+\mathrm{xLc} 1-$ $\mathrm{xLc} 2+\mathrm{xLp} / \mathrm{Lc} 2+\mathrm{xLc} 1-\mathrm{xLc} 2$, there will be $d(F(y)) /\left.\mathrm{d} y\right|_{y=1}$ $\langle 0$, and $y=1$ is the ESS of the system. When $z\rangle \mathrm{Cp} 2-\mathrm{Cp} 1+$ $\mathrm{Lc} 2+\mathrm{xLc1}-\mathrm{xLc} 2+\mathrm{xLp} / \mathrm{Lc} 2+\mathrm{xLc1}-\mathrm{xLc} 2$, there will be $d(F(y)) /\left.\mathrm{d} y\right|_{y=0}\langle 0$, and $y=0$ is the ESS of the system. The phase diagram of social capitals' behavioral strategy evolution is shown in Figure 2. The surface $z=\mathrm{Cp} 2-\mathrm{Cp} 1+$ $\mathrm{Lc} 2+\mathrm{xLc} 1-\mathrm{xLc} 2+\mathrm{xLp} / \mathrm{Lc} 2+\mathrm{xLc} 1-\mathrm{xLc} 2$ divides the three-dimensional space $V=(x, y, z \mid, 0 \leq x \leq 1,0 \leq y \leq$ $1,0 \leq z \leq 1)$ into parts of $V 1$ and $V 2$. In part $V 1$, social capitals gradually evolved to $y=1$ and finally chose the strategy of "positive adoption." In part V2, social capitals gradually evolved to $y=0$ and finally chose the strategy of "passive adoption."

3.2.3. Replicator Dynamics Equation and Equilibrium Point Analysis of Contractors. According to Table 2, we can get the perceived expected value $E_{c 1}$ of contractors taking strategy of "positive application" and the perceived expected value $E_{c 2}$ of contractors taking strategy of "passive application."

$$
\begin{aligned}
\mathrm{Ec} 1 & =\mathrm{xy}(\mathrm{Rc}-\mathrm{Cc}+\mathrm{Sc})+y(1-x)(\mathrm{Rc}-\mathrm{Cc}+\mathrm{Sc})+(1-y)(1-x)(\mathrm{Rc}-\mathrm{Cc}+\mathrm{Sc}) \\
& =\mathrm{Rc}-\mathrm{Cc}+\mathrm{Sc} \\
\mathrm{Ec} 2 & =\mathrm{xy}(-\mathrm{Lc}-\mathrm{Lc} 1)+y(1-x)(-\mathrm{Lc} 2)+x(1-y)(-\mathrm{Lc})+(1-y)(1-x)(0)=x y \mathrm{Lc} 2-x \mathrm{Lc}-\mathrm{yLc}-\mathrm{xyLc}
\end{aligned}
$$




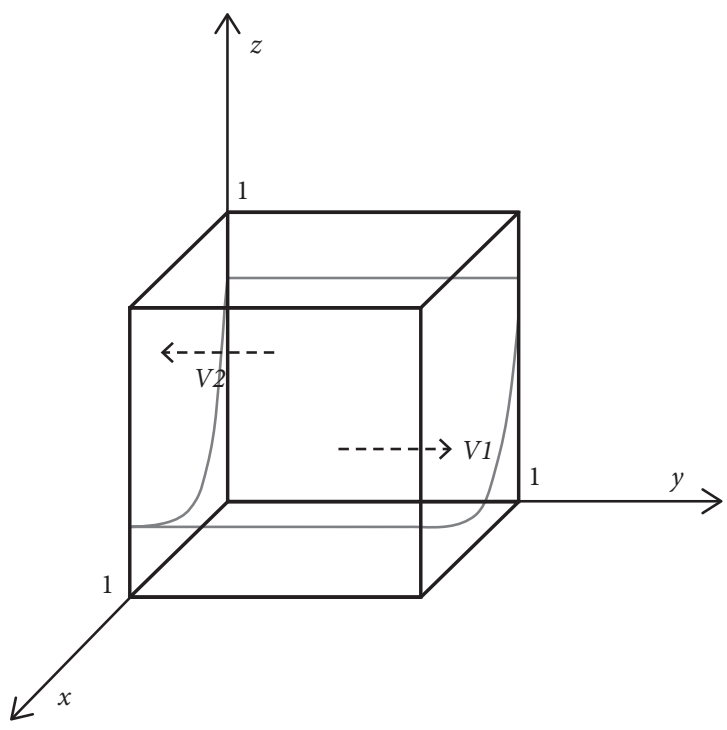

Figure 2: Phase diagram of social capitals' behavioral strategy evolution.

Then, the average perceived expected value of contractors is as follows:

$$
\overline{E_{c}}=z E_{c 1}+(1-z) E_{c 2} .
$$

Therefore, the replication dynamic equation of contractors is as follows:

$$
\begin{aligned}
F(z) & =\frac{\mathrm{d} z}{\mathrm{~d} t}=z(\mathrm{Ec} 1-\overline{\mathrm{Ec}})=z(1-z)(\mathrm{Ec} 1-\mathrm{Ec} 2) \\
& =z(1-z)(\mathrm{Rc}-\mathrm{Cc}+\mathrm{Sc}+\mathrm{xLc}+\mathrm{yLc} 2+\mathrm{xyLc} 1-\mathrm{xyLc} 2) .
\end{aligned}
$$

The first derivative of $z$ is equal to
$\frac{d(F(z))}{\mathrm{d} z}=(1-2 z)(\mathrm{Rc}-\mathrm{Cc}+\mathrm{Sc}+\mathrm{xLc}+\mathrm{yLc} 2+\mathrm{xyLc1}-\mathrm{xyLc2})$.

When $F(z)=0$ and $d(F(z)) / \mathrm{d} z\langle 0$, contractors' strategy of "positive application" will be in a stable state. Therefore, there will be $F(z) \equiv 0$ when $y=\mathrm{Rc}-\mathrm{Cc}+\mathrm{Sc}+\mathrm{xLc} /$ $x(\mathrm{Lc} 2-\mathrm{Lc} 1)-\mathrm{Lc} 2$, and all the values of $z$ are in a stable state. When $y\langle\mathrm{Rc}-\mathrm{Cc}+\mathrm{Sc}+\mathrm{xLc} / x(\mathrm{Lc} 2-\mathrm{Lc} 1)-\mathrm{Lc} 2$, there will be $d(F(z)) /\left.\mathrm{d} z\right|_{z=1}\langle 0$, and $z=1$ is the ESS of the system. When $y>\mathrm{Rc}-\mathrm{Cc}+\mathrm{Sc}+\mathrm{xLc} / x(\mathrm{Lc} 2-\mathrm{Lc} 1)-\mathrm{Lc} 2$, there will be $d(F(z)) /\left.\mathrm{d} z\right|_{z=0}\langle 0$, and $z=0$ is the ESS of the system. The phase diagram of contractors' behavioral strategy evolution is shown in Figure 3. The surface $y=$ $\mathrm{Rc}-\mathrm{Cc}+\mathrm{Sc}+\mathrm{xLc} / x(\mathrm{Lc} 2-\mathrm{Lc} 1)-\mathrm{Lc} 2$ divides the threedimensional space $V=(x, y, z \mid, 0 \leq x \leq 1,0 \leq y \leq 1,0 \leq$ $z \leq 1)$ into parts of $V 1$ and $V 2$. In part $V 1$, contractors gradually evolved to $z=1$ and finally chose the strategy of "positive application." In part $V 2$, contractors gradually evolved to $z=0$ and finally chose the strategy of "passive application."

3.3. Evolutionary Stability Analysis. The Jacobin matrix of the system is represented by $J$ :

$$
J=\left[\begin{array}{lll}
J_{1} & J_{2} & J_{3} \\
J_{4} & J_{5} & J_{6} \\
J_{7} & J_{8} & J_{9}
\end{array}\right]=\left[\begin{array}{lll}
\frac{\partial f(x)}{\partial x} & \frac{\partial f(x)}{\partial y} & \frac{\partial f(x)}{\partial z} \\
\frac{\partial f(y)}{\partial x} & \frac{\partial f(y)}{\partial y} & \frac{\partial f(y)}{\partial z} \\
\frac{\partial f(z)}{\partial x} & \frac{\partial f(z)}{\partial y} & \frac{\partial f(z)}{\partial z}
\end{array}\right] .
$$

Among them,

$$
\begin{aligned}
& \frac{\partial f(x)}{\partial x}=(1-2 x)(\mathrm{Cg} 2-\mathrm{Cg} 1+\mathrm{Lg}-\mathrm{Sp}+\mathrm{Lp}+\mathrm{Lc}-\mathrm{zLc}-\mathrm{yLp}-\mathrm{zLg}), \\
& \frac{\partial f(y)}{\partial y}=(1-2 y)(\mathrm{Cp} 2-\mathrm{Cp} 1+\mathrm{Lc} 2+\mathrm{xLc} 1-\mathrm{xLc} 2-\mathrm{zLc} 2+\mathrm{xLp}-\mathrm{xzLc} 1+\mathrm{xzLc} 2) \\
& \frac{\partial f(z)}{\partial z}=(1-2 z)(\mathrm{Rc}-\mathrm{Cc}+\mathrm{Sc}+\mathrm{xLc}+\mathrm{yLc} 2+\mathrm{xyLc} 1-\mathrm{xyLc} 2)
\end{aligned}
$$

The local stability of equilibrium points is given in Table 3.

According to the indirect method of Lyapunov, the equilibrium point is asymptotically stable if all its eigenvalues of the Jacobian matrix [56] have negative real parts. In Table 3, it can be seen that if we want the system evolving to the ESS point $(1,1,1)$, the following conditions must be met: $\mathrm{Cg}+\mathrm{Sp}<\alpha \mathrm{Lg} 1, \mathrm{Cp} 1<\mathrm{Cp} 2+\mathrm{Lp}$, and $\mathrm{Cc}<\mathrm{Rc}+\mathrm{Sc}$.

However, it should be noted that in the actual PPP projects, the main stakeholders cannot make the best use of the existing information in the decision-making because of their limited rationality. They usually make decisions through subjective judgment which ultimately leads to deviation in their behaviors. The deviations will hinder the establishment of ESS point $(1,1,1)$ and make the system difficult to converge to the optimal state. The reasons are analyzed based on the prospect theory as follows: take governments, for example, the condition that governments promoting BIM actively is $\mathrm{Cg}+\mathrm{Sp}<\alpha \mathrm{Lg} 1$. Based on the prospect theory, individuals always overestimate the low probability loss and underestimate the high probability gain, namely, individuals tend to choose risk aversion in the 


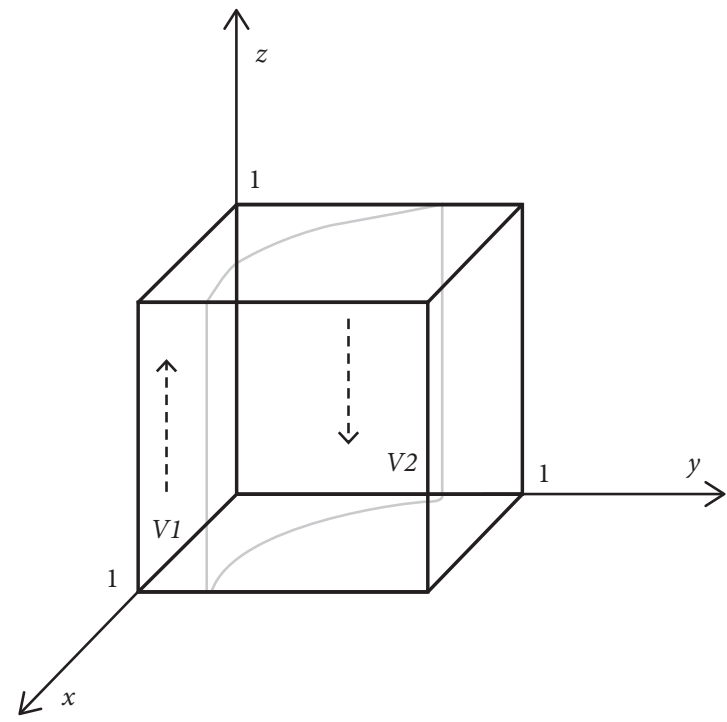

FIgURE 3: Phase diagram of contractors' behavioral strategy evolution.

TABLE 3: The eigenvalues of each equilibrium point.

\begin{tabular}{|c|c|c|c|}
\hline \multirow{2}{*}{ Equilibrium point } & \multicolumn{3}{|c|}{ Eigenvalues of Jacobi matrix } \\
\hline & $\lambda_{1}$ & $\lambda_{2}$ & $\lambda_{3}$ \\
\hline$E(0,0,0)$ & $-\mathrm{Cg}-\mathrm{Sp}+\mathrm{Lg}+\mathrm{Lp}+\alpha \mathrm{Lg} 1$ & $\mathrm{Cp} 2-\mathrm{Cp} 1+\mathrm{Lc} 2$ & $\mathrm{Rc}-\mathrm{Cc}+\mathrm{Sc}$ \\
\hline$E(1,0,0)$ & $\mathrm{Cg}+\mathrm{Sp}-\mathrm{Lg}-\mathrm{Lp}-\mathrm{Lc}-\alpha \mathrm{Lg} 1$ & $\mathrm{Cp} 2-\mathrm{Cp} 1+\mathrm{Lc} 1+\mathrm{Lp}$ & $\mathrm{Rc}-\mathrm{Cc}+\mathrm{Sc}+\mathrm{Lc}$ \\
\hline$E(0,1,0)$ & $-\mathrm{Cg}-\mathrm{Sp}+\mathrm{Lc}+\alpha \mathrm{Lg} 1$ & Cp2 - Cp $1-\mathrm{Lc} 2$ & $\mathrm{Rc}-\mathrm{Cc}+\mathrm{Sc}+\mathrm{Lc} 2$ \\
\hline$E(0,0,1)$ & $-\mathrm{Cg}-\mathrm{Sp}+\mathrm{Lc}+\alpha \mathrm{Lg} 1$ & $\mathrm{Cp} 2-\mathrm{Cp} 1$ & $-\mathrm{Rc}+\mathrm{Cc}+\mathrm{Sc}$ \\
\hline$E(1,1,0)$ & $\mathrm{Cg}+\mathrm{Sp}-\mathrm{Lc}-\alpha \operatorname{Lg} 1$ & $-\mathrm{Cp} 2-\mathrm{Cp} 1-\mathrm{Lc} 1-\mathrm{Lp}$ & $\mathrm{Rc}-\mathrm{Cc}+\mathrm{Sc}+\mathrm{Lc}+\mathrm{Lc} 1$ \\
\hline$E(1,0,1)$ & $\mathrm{Cg}+\mathrm{Sp}-\mathrm{Lp}-\mathrm{Lg}-\alpha \operatorname{Lg} 1$ & $\mathrm{Cp} 2-\mathrm{Cp} 1+\mathrm{Lp}$ & $-\mathrm{Rc}+\mathrm{Cc}-\mathrm{Sc}-\mathrm{Lc}$ \\
\hline$E(0,1,1)$ & $-\mathrm{Cg}-\mathrm{Sp}+\alpha \mathrm{Lg} 1$ & $-\mathrm{Cp} 2+\mathrm{Cp} 1$ & $-\mathrm{Rc}+\mathrm{Cc}-\mathrm{Sc}-\mathrm{Lc} 2$ \\
\hline$E(1,1,1)$ & $\mathrm{Cg}+\mathrm{Sp}-\alpha \operatorname{Lg} 1$ & $-\mathrm{Cp} 2-\mathrm{Cp} 1+\mathrm{Lp}$ & $-\mathrm{Rc}+\mathrm{Cc}-\mathrm{Sc}-\mathrm{Lc}-\mathrm{Lcl}$ \\
\hline
\end{tabular}

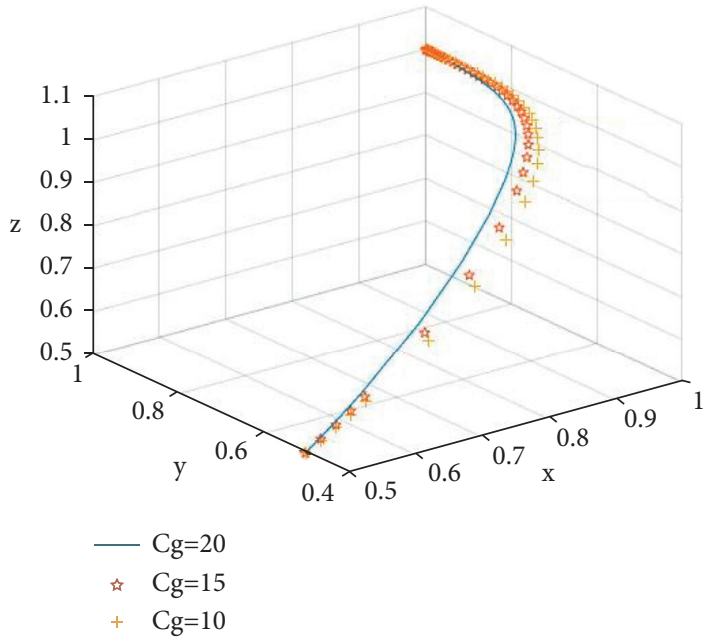

(a)

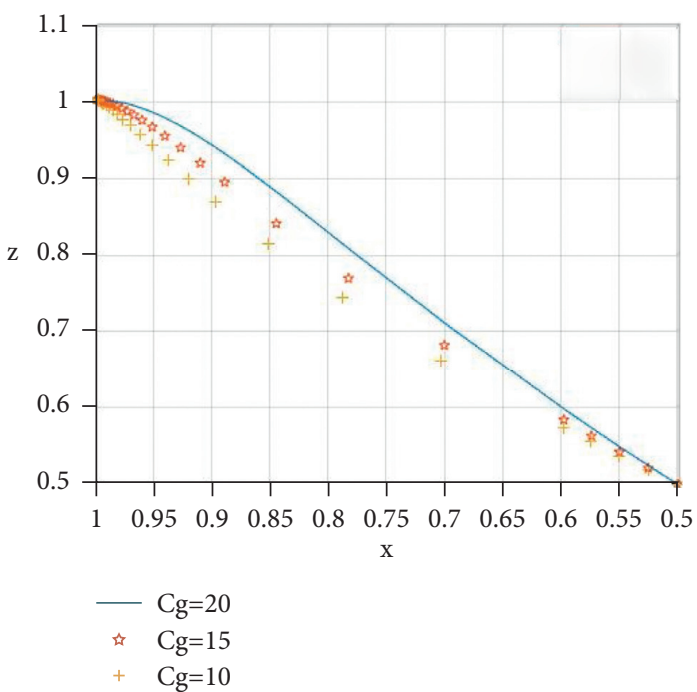

(b)

FIGURE 4: Influence of $\mathrm{Cg}$ change on the evolutionary game process. 


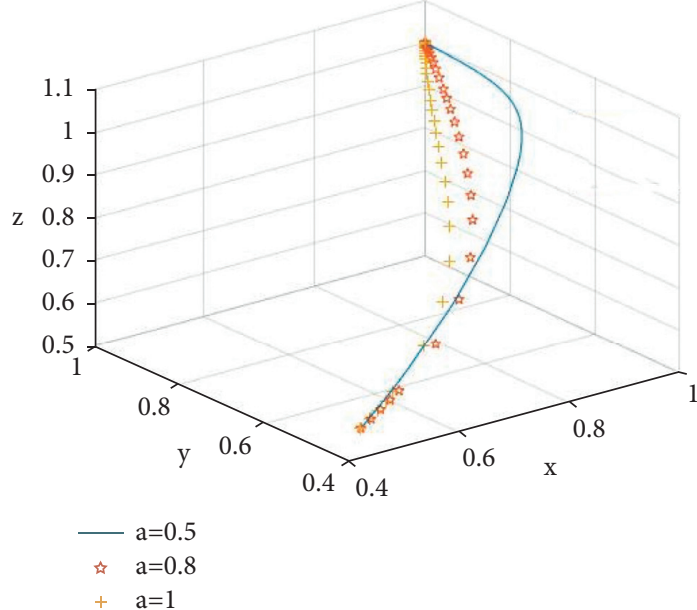

(a)

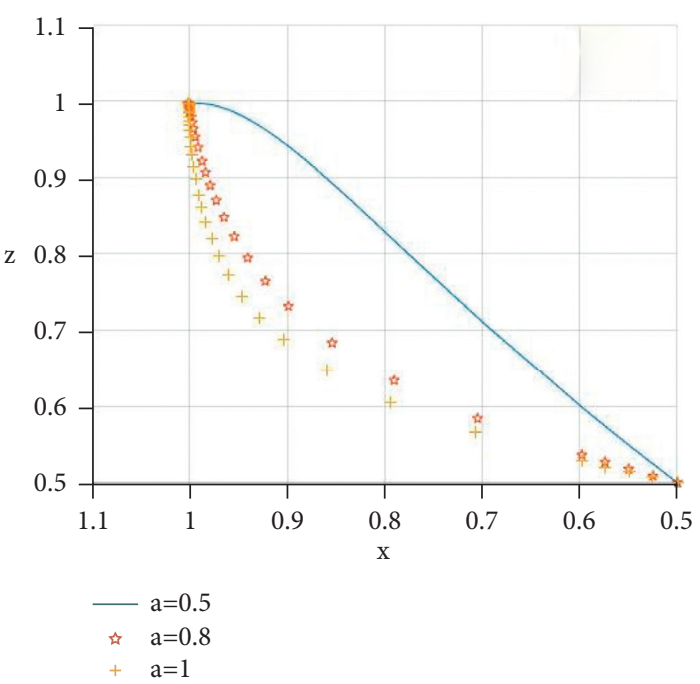

(b)

FIGURE 5: Influence of $\alpha$ change on the evolutionary game process.

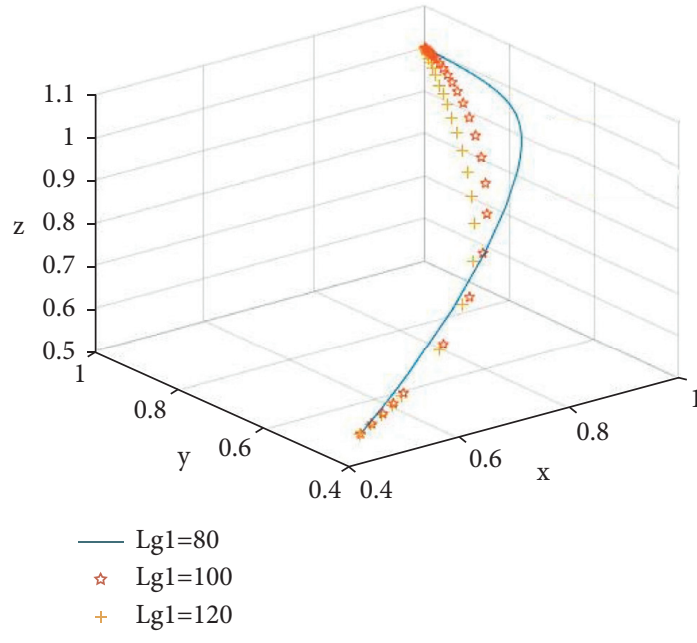

(a)

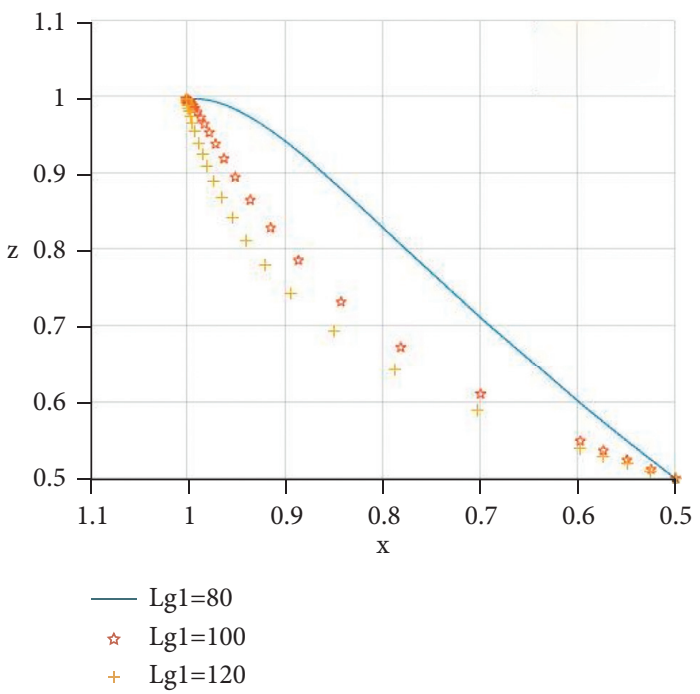

(b)

Figure 6: Influence of Lg1 change on the evolutionary game process.

face of gains, but tend to prefer risk preference when facing losses [57]. In the practice of PPP projects, governments often think that their behavior will not be easily detected by the superior supervision authority due to the common existence of fluke mentality. Therefore, governments tend to underestimate the probability $\alpha$ and the value of punishment Lg1 by the superior supervision authority, which means that the right part of the conditional formula $\mathrm{Cg}+\mathrm{Sp}<\alpha \operatorname{Lg} 1$ will be underestimated in practice. On the other hand, when governments choose the active strategy, it will definitely pay the promotion cost, while choosing the passive strategy will only have a certain probability of punitive losses. According to the prospect theory, governments will be more inclined to risk preference, that is, they prefer to take risks and choose the passive strategy rather than to bear the deterministic expenditure. Therefore, the above reasons will cause certain difficulties for the establishment of the formula $\mathrm{Cg}+\mathrm{Sp}<\alpha \operatorname{Lg} 1$.

\section{Numerical Simulation and Analysis}

In order to better analyze the behavior evolution mechanism among governments, social capitals and contractors in BIM adoption, this study uses MATLAB R2018a to simulate the trend and influencing factors of the evolutionary game. The values of parameters are randomly assigned under the assumption, which do not represent the real benefits of stakeholders in PPP projects.

According to the above analysis, if the system converges to the ESS point $(1,1,1)$, the following conditions need to be 


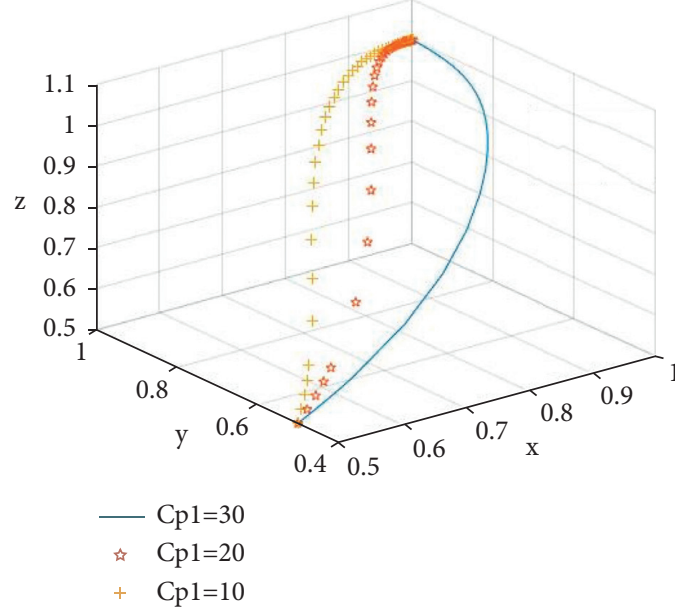

(a)

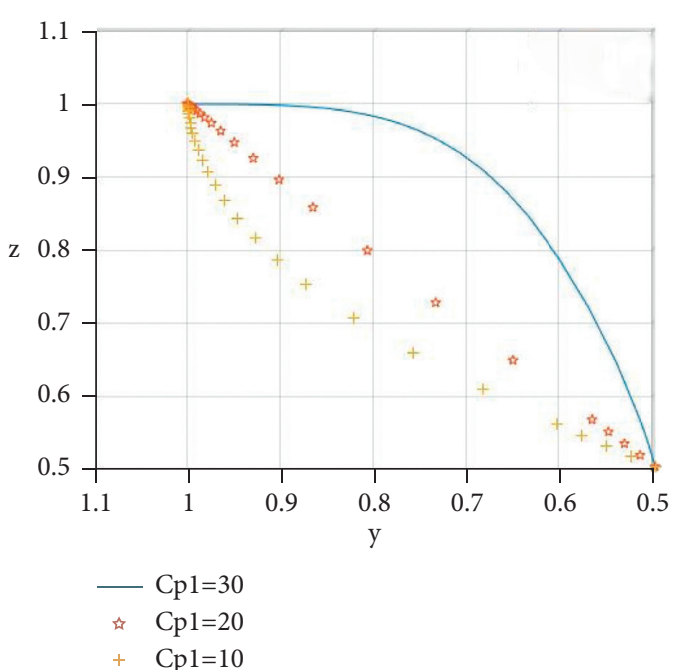

(b)

Figure 7: Influence of $\mathrm{Cp} 1$ change on the evolutionary game process.

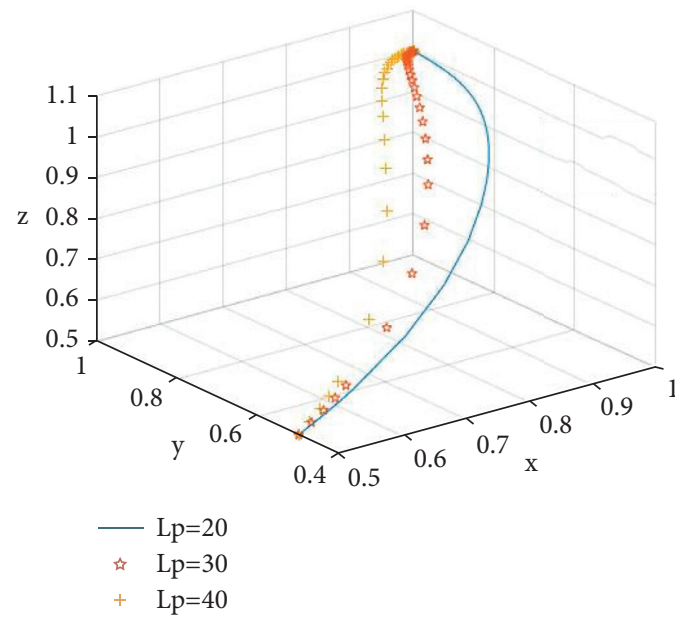

(a)

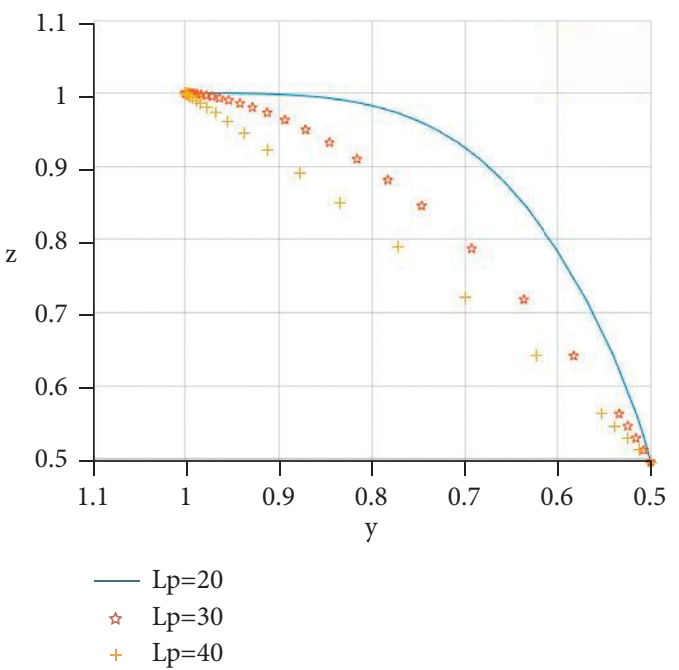

(b)

FiguRE 8: Influence of Lp change on the evolutionary game process.

satisfied: $\mathrm{Cg}+\mathrm{Sp}<\alpha \mathrm{Lg} 1, \mathrm{Cp} 1<C p 2+\mathrm{Lp}$, and $\mathrm{Cc}<\mathrm{Rc}+\mathrm{Sc}$. The initial values of each parameter are set to $x=0.5, y=$ $0.5, \alpha=0.5, \mathrm{Cg}=20, \mathrm{Sp}=10, \mathrm{Lgl}=80, \mathrm{Cp} 1=30, \mathrm{Cp} 2=$ $20, \mathrm{Sp}=10, \mathrm{Lg} 1=80, \mathrm{Cp} 1=30, \mathrm{Cp} 2=20, \mathrm{Lp}=20, \mathrm{Cc}=$ $30, \mathrm{Rc}=40, \mathrm{Sc}=10, \mathrm{Lg}=10, \mathrm{Lc}=10, \mathrm{Lc} 1=10, \mathrm{LC} 2=5$.

\subsection{Influence of Cg1 and Cg2 Changes on the Evolutionary} Game Process. Keep the other parameters unchanged, and the influence on the evolution trend of the system is observed by changing the values of $\mathrm{Cg}, \alpha$, and $\operatorname{Lg} 1$, as shown in Figures 4(a), 5(a), and 6(a). In Figure 4(b), we can see that the convergence rate of $x$ to the ESS point $(1,1,1)$ is accelerated as the value of $\mathrm{Cg}$ goes down. The simulation results show that reducing the cost of governments' strategy of "positive promotion" is helpful to enhance the willingness of governments to promote the adoption of BIM in PPP projects. In Figures 5(b) and 6(b), we can see that the convergence rate of $x$ to the ESS point $(1,1,1)$ is accelerated as the value of $\alpha$ and $\operatorname{Lg} 1$ go bigger. The simulation results show that increasing the supervision probability and the severity of punishment will help increase the willingness of governments to promote BIM application in PPP projects.

\subsection{Influence of CP1 and Lp Changes on the Evolutionary} Game Process. Keep the other parameters unchanged, and the influence on the evolution trend of the system is observed by changing the values of Cp1 and Lp, as shown in Figures 7(a) and 8(a). In Figure 7(b), we can see that the convergence rate of $y$ to the ESS point $(1,1,1)$ is accelerated as the value of $\mathrm{Cp} 1$ goes down. The simulation results show 


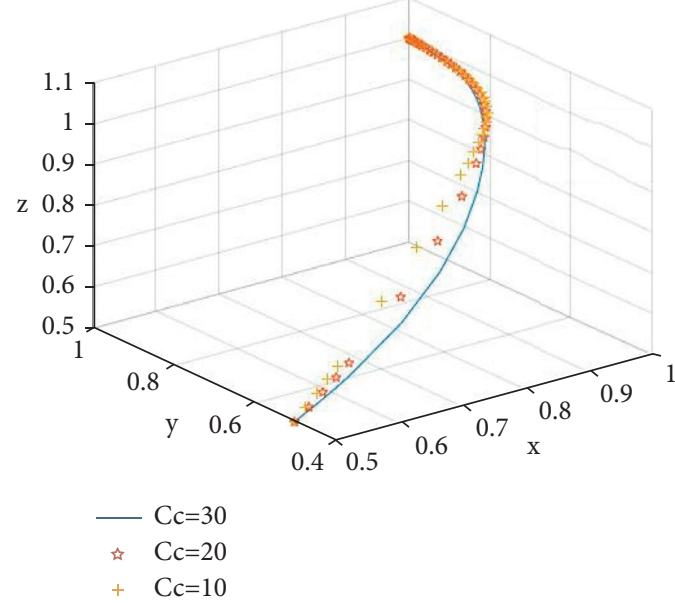

(a)

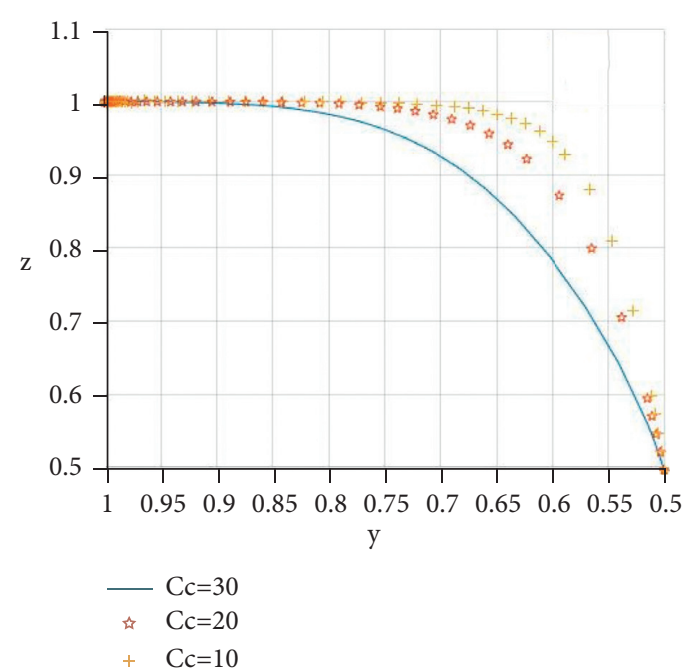

(b)

Figure 9: Influence of Cc change on the evolutionary game process.

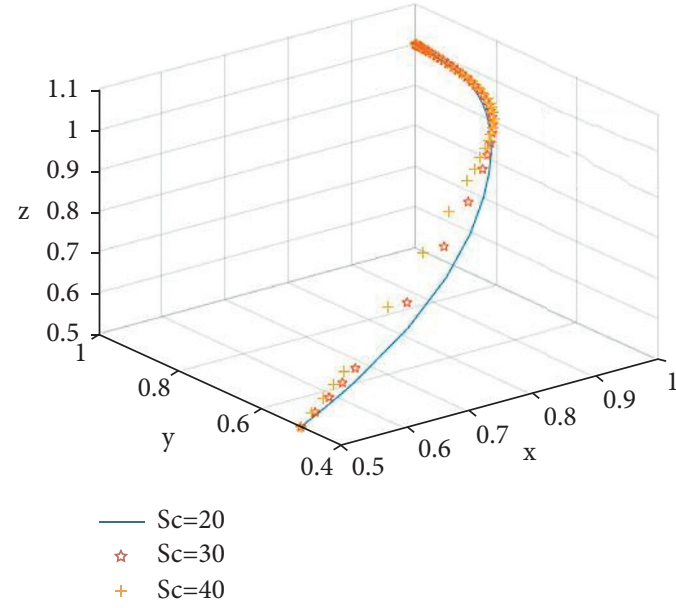

(a)

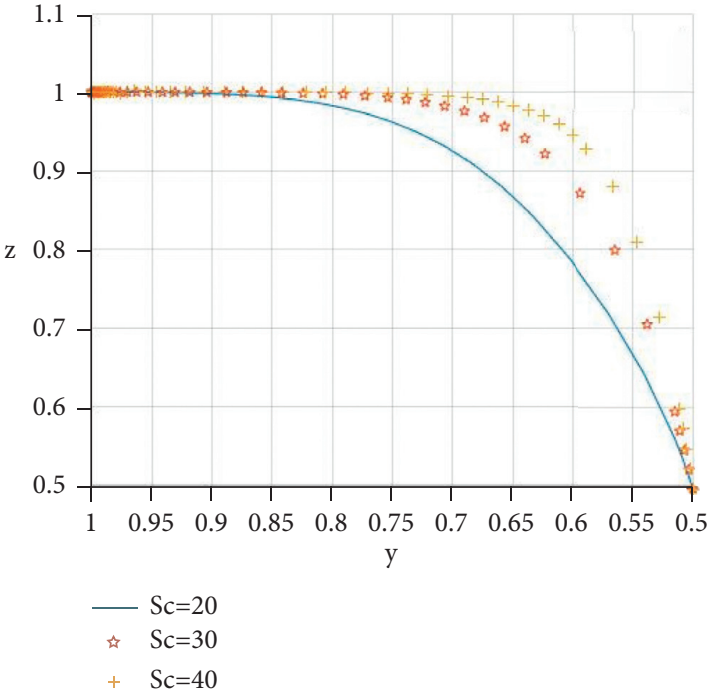

(b)

Figure 10: Influence of Sc change on the evolutionary game process.

that reducing the cost of social capitals' strategy of "positive adoption" is helpful to enhance the willingness of social capitals to adopt BIM in PPP projects. In Figure 8(b), we can see that the convergence rate of $y$ to the $\operatorname{ESS}$ point $(1,1,1)$ is accelerated as the value of Lp goes bigger. The simulation results show that increasing the punishment of social capitals' strategy of "passive adoption" is helpful to enhance the willingness of social capitals to adopt BIM in PPP projects.

\subsection{Influence of $C c$ and Sc Changes on the Evolutionary Game} Process. Keep the other parameters unchanged, and the influence on the evolution trend of the system is observed by changing the values of $\mathrm{Cc}$ and Sc, as shown in Figures 9(a) and 10(a). In Figure 9(b), we can see that the convergence rate of $z$ to the ESS point $(1,1,1)$ is accelerated as the value of $C c$ goes down. The simulation results show that reducing the cost of contractors' strategy of "positive application" is helpful to enhance the willingness of contractors to apply BIM in PPP projects. In Figure 10(b), we can see that the convergence rate of $z$ to the ESS point $(1,1,1)$ is accelerated as the value of Sc goes bigger. The simulation results show that increasing the punishment of contractors' strategy of "passive application" is helpful to enhance the willingness of contractors to apply BIM in PPP projects.

\section{Conclusions and Management Implications}

Under the assumption of bounded rationality, this study constructs a tripartite evolutionary game model including 
governments, social capitals, and contractors. The satisfaction conditions that the system converging to the ESS point $(1,1,1)$ are analyzed based on prospect theory, and the main factors influencing stakeholders' behavior decision-making are simulated by MATLAB. The research results will help to clarify the behavior evolution mechanism and the influencing factors of the ESS for adopting BIM among stakeholders in PPP projects, so as to improve the crossorganization information collaboration efficiency of PPP projects and promote the informatization of the construction industry. The primary conclusions and management implications are as follows.

First, the cost of BIM promotion by governments and the punishment from the superior supervision authority when governments choose the passive strategy are the key factors affecting governments' behavior choice. When governments actively promote the cost reduction of BIM or punished more by the superior supervision authority, governments will choose the active promotion strategy and the behavior gradually converges to the ESS point $(1,1,1)$.

Second, the cost of active adoption of BIM and the punishment of passive adoption of BIM are the key factors affecting the choice of social capitals' behavior. When the cost of active adoption of BIM is reduced or the penalty of passive adoption of BIM is increased, the intention of social capitals to choose active adoption of BIM strategy is increased, and the behavior of social capitals gradually converges to the ESS point $(1,1,1)$.

Finally, the cost of active application of BIM and the reward of active application of BIM are the key factors influencing the choice of contractors' behavior. When the cost of the active application of BIM technology is reduced or the penalty of the negative application of BIM technology is increased, the intention of the contractor to choose the strategy of active application of BIM technology is increased, and the contractor's behavior gradually converges to the ESS point $(1,1,1)$.

The adoption of BIM in PPP projects is a major reform of the traditional building mode, which requires all stakeholders to change the traditional thinking and actively cooperate. In order to promote BIM adoption among stakeholders of PPP projects, the following management implications are proposed: Improve the supervision efficiency of superior supervision authority on governments' promotion of BIM and further enrich the supervision means with the help of the media and the public. Increase the punishment for the governments' passive promotion of BIM, so as to improve the perceived value of governments for regulatory punishment.

Strengthen the punishment for the passive adoption of BIM by social capitals and the reward for the active application of BIM by contractors. Improve the cognition of social capitals and contractors on BIM and other advanced information technology through publicity and training and gradually transform the system promotion into habitual adoption.

Under the PPP mode, the adoption of BIM can be promoted by the government's supervision, but the government's behavior also needs supervision. The public is the users and beneficiaries of PPP projects' goods, and the public should also have the right to know and to supervise the implementation of the projects. Therefore, in the next stage, the authors will further research the role of public supervision in the adoption of BIM in PPP projects, in order to explore the evolutionary mechanism and influencing factors under more stakeholders.

\section{Data Availability}

Some or all data, models, or code generated or used to support the findings of this study are available from the corresponding author upon request.

\section{Conflicts of Interest}

The authors declare that there are no conflicts of interest.

\section{Acknowledgments}

This work was supported by the National Natural Science Foundation of China (NSFC) (71801119), in part by the Social Science Planning Foundation of Liaoning (L18BGL020), and in part by the Basic Scientific Research Projects in Institutions of Higher Learning of Liaoning Education Department (LJ2017QW009).

\section{References}

[1] N. Carbonara and R. Pellegrino, "Revenue guarantee in public-private partnerships: a win-win model," Construction Management \& Economics, vol. 36, no. 10, pp. 584-598, 2018.

[2] L. Cheng, "Discussion on the application of PPP model in new infrastructure construction," Open Journal of Social Sciences, vol. 7, no. 9, pp. 283-288, 2019.

[3] D. Wu and S. Q. Wang, "Research development and trend of public private partnership in China," Journal of Engineering Management, vol. 28, no. 6, pp. 75-80, 2014.

[4] K. Leidel and H. W. Alfen, Lifecycle-Oriented Risk Management for PPP-Projects in Public Real Estate, pp. 587-604, Eres, Los Angeles, CA, USA, 2009.

[5] J. Yuan, X. Li, Y. Ke, W. Xu, Z. Xu, and M. Skibnewski, "Developing a building information modeling-based performance management system for public-private partnerships," Engineering, Construction and Architectural Management, vol. 27, no. 8, pp. 1727-1762, 2020.

[6] S. Jayasuriya, G. Zhang, and R. J. Yang, "Exploring the impact of stakeholder management strategies on managing issues in PPP projects," International Journal of Construction Management, vol. 20, no. 6, pp. 666-678, 2020.

[7] C. X. Jiang, "Causes and implications of the failure in transportation infrastructure public private partnerships-—a study of 25 typical PPP cases," Journal of Beijing Jiaotong University, vol. 15, no. 3, pp. 50-58, 2016.

[8] R. Osei-Kyei and A. P. C. Chan, "Review of studies on the critical success factors for public-private partnership (PPP) projects from 1990 to 2013," International Journal of Project Management, vol. 33, no. 6, pp. 1335-1346, 2015.

[9] B. Zhang, Y. Wang, X. Liu et al., "The configuration of PPP failure-Ca crisp-set qualitative comparative analysis," Journal of Public Administration, vol. 12, no. 04, pp. 65-81+191, 2019. 
[10] N. Costantino and R. Pellegrino, "Public-private partnership implementation: cross-case analysis," Proceedings of the Institution of Civil Engineers-management, Procurement and Law, vol. 168, no. 4, pp. 164-176, 2015.

[11] P. Zhang, K. Zhan, and Y. Zhou, "Game model of three-party shared risk allocation for PPP projects--based on the perspective of incomplete information," IOP Conference Series: Earth and Environmental Science, vol. 295, no. 4, pp. 42-49, 2019.

[12] N. W. Young, S. A. Jones, and H. M. Bernstein, Building Information Modeling: Transforming Design and Construction to Achieve Greater Industry Productivity, McGraw Hill Construction, New York, NY, USA, 2008.

[13] N. D. Aziz, A. H. Nawawi, and N. R. M. Ariff, "Building information modelling (BIM) in facilities management: opportunities to be considered by facility managers," ProcediaSocial and Behavioral Sciences, vol. 234, pp. 353-362, 2016.

[14] W. Zou, M. Kumaraswamy, and J. Chung, "Identifying the critical success factors for relationship management in PPP projects," International Journal of Project Management, vol. 32, no. 2, pp. 265-274, 2014.

[15] Q. Wang and T. Wang, "Research on promotion of BIM based on game analysis of stakeholders," Sichuan Building Materials, vol. 41 , no. 6 , p. $272+278,2015$.

[16] Q. L. Yin, Evolutionary Game Analysis on BIM Technology Diffusion of Prefabricated Construction, Qingdao University of Technology, Qingdao, China, 2019.

[17] H. X. Tang, J. M. Cao, H. S. Xu, and C. F. Han, “Analysis on BIM application cooperation behaviors in integrated facility management organization based on evolutionary game theory," Industrial Engineering \& Management, vol. 25, no. 4, pp. 1-8, 2020.

[18] J. R. Song, "Research on incentive and countermeasures of BIM application based on game theory," Value Engineering, vol. 36, no. 33, pp. 43-44, 2017.

[19] C. Jia, Z. H. Wang, and L. Zhao, "Evolutionary game analysis and simulation for cooperative application of BIM technology in PPP," Journal of Liaoning Technical University, vol. 22, no. 4, pp. 270-277, 2020.

[20] K. A. Tversky, "Prospect theory: an analysis of decision under risk," Econometrica, vol. 47, no. 2, pp. 263-291, 1979.

[21] R. L. Gao and Q. Bao, "Selection of government supervision mode during the operational period in PPP projects based on evolutionary game theory," Operations Research and Management Science, vol. 28, no. 4, pp. 155-162, 2019.

[22] S. K. He, G. W. Liang, and J. B. Meng, "Multi-subjects benefit game and behavior evolution mechanism of major engineering based on prospect theory," Science and Technology Management Research, vol. 40, no. 5, pp. 207214, 2020.

[23] A. Porwal and K. N. Hewage, "Building information modeling (BIM) partnering framework for public construction projects," Automation in Construction, vol. 31, no. 3, pp. 204-214, 2013.

[24] P. E. D. Love, J. Liu, J. Matthews, C.-P. Sing, and J. Smith, "Future proofing PPPs: life-cycle performance measurement and building information modelling," Automation in Construction, vol. 56, pp. 26-35, 2015.

[25] Y. L. Yin, Q. J. Liu, and X. Wang, "Research on the whole life cycle supervision system of public projects-_based on the collaboration of VfM evaluation and BIM technology," Project Management Technology, vol. 14, no. 07, pp. 17-20, 2016.

[26] S. Q. Wang, R. Tiong, S. Ting et al., "Evaluation and management of political risks in China's BOT projects," Journal of
Construction Engineering and Management, vol. 126, no. 3, pp. 242-250, 2000.

[27] Y. M. Chen and H. F. Chen, "The risk management of PPP project life cycle based on BIM technology," Project Management Technology, vol. 15, no. 5, pp. 51-55, 2017.

[28] G. Luo and X. X. Zhan, "Research on the application of BIM in PPP project whole-life cycle," Technology and Economic Guide, vol. 26, no. 5, p. 168, 2018.

[29] B. L. Zhou and C. L. Lin, "The application of BIM in PPP project whole-life cycle," Engineering Economy, vol. 29, no. 3, pp. 51-54, 2019.

[30] J. M. Smith, Evolution and the Theory of Games, Cambridge University Press, Cambridge, UK, 1982.

[31] J. W. Weibull, Evolutionary Game Theory, MIT Press, Cambridge, MA, USA, 1997.

[32] K. Binmore, "Modeling rational players: part I," Economics and Philosophy, vol. 3, no. 2, pp. 179-214, 1987.

[33] K. Binmore, "Modeling rational players: part II," Economics and Philosophy, vol. 4, 1988.

[34] P. D. Taylor and L. B. Jonker, "Evolutionarily stable strategies and game dynamics," Mathematical Biosciences, vol. 40, no. 12, pp. 145-156, 1978.

[35] P. Young, "Conventional contracts," The Review of Economic Studies, vol. 65, no. 4, pp. 773-792, 1998.

[36] D. Fudenberg and C. Harris, "Evolutionary dynamics with aggregate shocks," Journal of Economic Theory, vol. 57, no. 2, pp. 420-441, 1992.

[37] H. Bester, W. Guth, and W. Güth, "Is altruism evolutionarily stable?" Journal of Economic Behavior \& Organization, vol. 34, no. 2, pp. 193-209, 1998.

[38] K. E. Boulding, R. R. Nelson, and S. G. Winter, "An evolutionary theory of economic chang," American Journal of Agricultural Economics, vol. 66, no. 4, p. 535, 1984.

[39] S. Y. Xie, Economic Game Theory, Fudan University Press, Shanghai, China, 2002.

[40] D. Friedman and K. C. Fung, "International trade and the internal organization of firms: an evolutionary approach," Journal of International Economics, vol. 41, no. 1-2, pp. 113137, 1996.

[41] Y. P. Wang and W. D. Meng, "Evolutionary game analysis on co-competition mechanism of supply chain," Journal of Industrial Engineering and Engineering Management, vol. 18, no. 2, pp. 96-98, 2004.

[42] J. Gao and Z. H. Shen, "Elementary groping for evolutionary game theory and its application in electricity market," $A u$ tomation of Electric Power Systems, vol. 27, no. 18, pp. 18-21, 2003.

[43] Y. Zhang and M. Guizani, Game Theory for Wireless Communications and Networking, CRC Press, Boca Raton, FL, USA, 2011.

[44] F. Y. Lu, "Evolutionary game analysis on environmental pollution problem," Systems Engineering-Theory \& Practice, vol. 27, no. 9, pp. 148-152, 2007.

[45] S. L. Dreisbach, "Impact of psychological research on moral theory: prospect theory and the doctrine of doing and allowing," Dissertations \& Theses-Gradworks, University of California, Santa Cruz, CA, USA, 2012.

[46] D. Kahneman and A. Tversky, "Prospect theory: an analysis of decision under risk," Econometrica, vol. 47, no. 2, 1979.

[47] N. C. Barberis, "Thirty years of prospect theory in economics: a review and assessment," The Journal of Economic Perspectives, vol. 27, no. 1, pp. 173-196, 2013. 
[48] S. Benartzi and R. H. Thaler, "Myopic loss aversion and the equity premium puzzle," Quarterly Journal of Economics, vol. 110, no. 1, pp. 73-92, 1995.

[49] N. Barberis and M. Huang, "Stocks as lotteries: the implications of probability weighting for security prices," The American Economic Review, vol. 98, no. 5, pp. 2066-2100, 2008.

[50] A. Frazzini, "The disposition effect and underreaction to news," The Journal of Finance, vol. 61, no. 4, pp. 2017-2046, 2006.

[51] W. Y. Hu and J. S. Scott, "Behavioral obstacles in the annuity market," Financial Analysts Journal, vol. 63, no. 6, pp. 71-82, 2007.

[52] B. Köszegi and M. Rabin, "Reference-dependent consumption plans," The American Economic Review, vol. 99, no. 3, pp. 909-936, 2009.

[53] P. Vamvakas, E. E. Tsiropoulou, and S. Papavassiliou, "Dynamic spectrum management in $5 \mathrm{G}$ wireless networks: a reallife modeling approach," in Proceedings of the IEEE INFOCOM 2019-IEEE Conference on Computer Communications IEEE, Paris, France, April 2019.

[54] Y. N. Zhou and J. C. Liu, "Study on supervision strategy of ppp project considering the participation of higher-level government," Chinese Journal of Management Science, vol. 1-16, 2021, https://doi.org/10.16381/j.cnki.issn1003-207x.2020. 0801.

[55] H. Q. Zhang, J. C. Wang, and H. L. Tao, "Research the decision-making behavior of investors based on prospect theory in the ppp project," Soft Science, vol. 32, no. 8, pp. 129-133, 2018.

[56] D. Friedman, "Evolutionary games in economics," Econometrica, vol. 59, no. 3, pp. 637-666, 1991.

[57] Z. B. Zhao and Q. P. Man, "Evolutionary game analysis of risk management behavior of major infrastructure projects based on projects based on prospect theory," Journal of Systems Management, vol. 27, no. 1, pp. 112-120, 2018. 